Association for Information Systems

AIS Electronic Library (AISeL)

\title{
Challenges in Digital Work - Exploring Solutions to Improve Team Identification in Virtual Teams
}

Geeske von Thülen

LMU Munich, Munich, Germany

Eva Hartl

LMU Munich, Munich, Germany

von Thülen, Geeske and Hartl, Eva, "Challenges in Digital Work - Exploring Solutions to Improve Team Identification in Virtual Teams" (2021). Wirtschaftsinformatik 2021 Proceedings. 2.

https://aisel.aisnet.org/wi2021/MSocialMedia13/Track13/2

This material is brought to you by the Wirtschaftsinformatik at AIS Electronic Library (AISeL). It has been accepted for inclusion in Wirtschaftsinformatik 2021 Proceedings by an authorized administrator of AIS Electronic Library (AISeL). For more information, please contact elibrary@aisnet.org. 


\title{
Challenges in Digital Work - Exploring Solutions to Improve Team Identification in Virtual Teams
}

\author{
Geeske von Thülen ${ }^{1}$, Eva Hartl² \\ ${ }^{1}$ LMU Munich, Munich, Germany \\ geeskevonthuelen@gmx.de \\ 2 LMU Munich, Munich, Germany \\ hartl@bwl.lmu.de
}

\begin{abstract}
The emergence of digital work leads to an increasing number of teams that collaborate virtually. The physical absence of team members and other problems that occur due to the virtual context hinder the formation of team identification, which however is essential for employee's work motivation and team effectiveness. Our study addresses the question of how companies can improve team identification in virtual teams. Combining a literature review with interviews with five case teams, we derive an overview of solutions to improve team identification and link these to problems in virtual team identification. Our results provide guidance to practitioners and we further derive propositions for future research based on identified research gaps and inconsistencies.
\end{abstract}

Keywords: Virtual Teams, Team Identification, Digital Work, Remote Work, Enterprise Social Media

\section{$1 \quad$ Introduction}

The rapid development of new digital technologies is characterizing our current business era. New technological opportunities combined with social and economic trends, like globalization or vertically-aligned corporate structures, are triggers for the emergence of digital work, in which ever more teams are locally distributed and have to collaborate virtually [1]. Virtual teams (VT) are characterized by not being located in the same physical space and using computer-mediated communications. Thus, they do have only little physical contact [2].

Researchers argue that physical absence of team members can reduce team identification (TI) [3] and that the establishment of TI with computer-mediated communication is difficult [4] as well as time- and effort-intense [5]. TI however is an important contributor to the success of teams as it describes the degree to which members align their personal interest to the team's and thereby determines their work engagement [6]. TI can thus increase team performance, bonding, and satisfactions and reduce team conflicts [7]. Missing TI negatively impacts team performance [8], team consensus [9] and individual interaction [10]. Thus, TI is a crucial prerequisite for team success. With COVID-19 having led to a sudden increase of virtual collaboration and 
with an expected increase in VT also in future, firms urgently need to find solutions for how to achieve and uphold TI in a virtual context.

Motivated by recent relevance of the topic and urgent need of practitioners, this study therefore addresses the question: what are solutions to improve TI in VT? This paper thereby intends to improve three issues with existing literature: 1) presented solutions are scattered throughout literature and an overview is missing, what issues yet need solving, 2) recent research criticizes that literature is lacking behind practice and suggests that existing findings in literature need to be extended by recent developments in practice, and 3) some solutions in literature hold paradoxes which require solving. We combine an extensive literature review with interview research to provide an extensive overview of solutions to improve TI in VT and give insights into their practical application. Based on the TI process, we first outline problems in team identification that occur due to the virtual context of teams. The results of our study then provide an overview of solutions to improve TI in VT and how they solve problems in virtual team identification. Our results provide practitioners with guidance and allow us to identify promising areas for future research.

\section{Theoretical Background}

\section{$2.1 \quad$ Team Identification}

Based on Tajfel's (1978) concept of social identity, team identification (TI) can be defined as the sharing of common goals with the team and feeling of psychological belongingness to and connection with the team's kismet. TI stems from the basic human tendency to classify oneself and others into social categories. Social identity theory and social categorization theory propose that individuals ascribe certain categorical characteristics of a group to themselves and thereby start to identify with that group and to integrate the specific categories into their self-concept [11,12]. With many citations and a high level quality rank, the paper of Fiol and O'Connor (2005) is the very central paper in the TI discipline. Since there are barely any concrete TI processes present in existing literature, we combine their model of the TI process with insights from Thatcher and Zhu (2006) and Lembke and Wilson (1998) [8], to give a holistic fivephase model beyond the state of the identification decision that guides our research [see Figure 1].

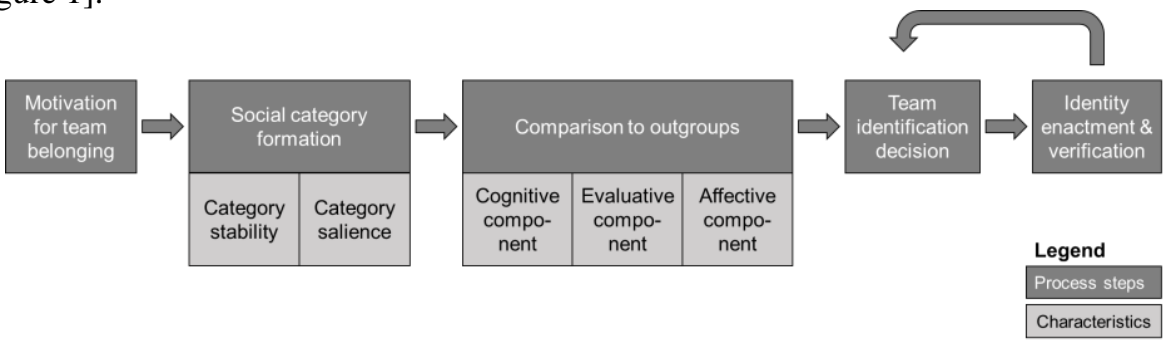

Figure 1. Depiction of team identification process. 
First, the motivation of the individuals to belong to a team (in-group) is an essential prerequisite for TI. In VT, this motivation stems predominantly from the desire to reduce existing subjective uncertainties, such as on relationships with others $[13,14]$. Given their motivation, individuals form social categories based on the team's characteristics that are meaningful to the individual [15] and make the team stand out from other teams (out-groups) [16]. Social category formation is influenced by the team's category stability, i.e. how consistent the team characteristics are perceived to be, and category salience, i.e. the degree of perceived importance of the team as an identification target. Subsequent to category formation, the team's characteristics are compared to the individuals' self-concept and relevant out-groups based on cognitive, evaluative, and affective components $[17,18]$. Thereby, a strong congruence between the individual's self-concept and the group's characteristics [12], a high valuation of the group membership [18], and an emotional attachment to the group [19] as well as perceived benefits of the team membership are desirable [20, 21]. In the resulting team identification itself, individuals adopt the team's characteristics to their self-concept [22]. However, in order for sustained TI, individuals need to enact the team identity by behaving accordingly to the team's characteristics and receive confirmation on the identity by others (verification), which reduces the risk of team members to lose identification with the team or start seeking other identifications.

\subsection{Virtual Teams}

VT are characterized by being distinct to traditional work teams in that they are (at least partly) geographically or organizationally separated and thus have a significant lower or even absent physical contact [13]. Based on the degree of geographical and organizational separation of the team, VT are distinguished into purely virtual and hybrid VT. This paper adopts the notion of VT as pure virtual, if all team members are geographically distributed from each other and do not have physical contact on a regular basis. We use the term hybrid VT, when there is some physical contact [13] and/ or when some, but not all, team members are located at the same site (onsite) whereas other members are geographically dispersed [23].

With VT becoming ever more important in practice due to technological developments, also research in this field has significantly increased since 2000 [24]. VT have been studied on individual, group and organizational level [24]. Thematically, VT research has investigated factors impacting VT work, such as leadership, team compositions and communication technologies [e.g. 25], VT processes and activities, such as knowledge management [e.g. 26] or identity [e.g. 3], as well as from VT resulting output factors, such as performance indicators, like team efficiency [e.g. 27] and team satisfaction [e.g. 1] [for a literature overview cf. 24, 28]. This growing body of research suggests that the particularities of VT lead to multiple problems along the TI process. The subsequent overview of problems for TI in virtual work was compiled based on our literature review (see section 3 for methodological details). From this literature review, we identified a list of problems that we set in relation to the TI process dependent on where in the process the problem was found to hinder TI. We further grouped the problems into 4 themes based on common causes: physical absence of team 
members, computer-mediated communication, team diversity, and volatile organizational environments.

One central characteristic of VT is the physical absence of team members which hinders TI in multiple ways. The absence of team members leads to a low external visibility of the team as an entity, thus reduces the desirability of the team as an identification target and reduces identification effort. Physical absence evokes social distance which further reduces the motivation to establish a positive team orientation which can result in reduced openness in communication and can negatively impact group process contentment [29]. Since physical distance leads to a decreased interaction between team members [3] it also negatively impacts identity enactment and verification and thus decreases the chance for mutual team member identity verification [5]. Also, the presence of external groups might negatively impact TI. Members of VT are often physically surrounded by different groups of other people. The higher visibility and identification salience of external groups thus threatens the identification with the specific VT [3]. While in pure VT all members work remotely from each other, in hybrid VT some members do work also physically together - a circumstance that might lead to subgroup identification in hybrid teams. The geographical closeness to some team members [30] as well as the higher frequency of interaction and physical meetings between collocated team members compared to the intensity of interaction with the physical distant members lead to the fact that the collocated employees tend to forget about the remote ones [29]. The higher level of interaction also reveals more identity cues of the team members and thereby fosters the visibility of similarities within this perceived in-group [13]. Additionally, literature suggests that there is a level of mistrust coming from people working onsite towards the work efficiency of remotely working employees, which negatively impacts the building of overall TI [3, 29].

With only little or no physical contact, VT have to rely on computer-mediated communication. Lean communication technology, such as E-Mail, is characterized by not having many features to transfer communication cues, such as gestures and mimes. This leads to ineffective communication [3] and might trigger intra-team conflicts due to misunderstandings [31]. Communication via lean technologies also reduces the speed of communication, thereby the number of interactions and leads to an overall reduced visibility of team members - ultimately resulting in reduced team identity salience [4]. Paradoxically, also rich media, such as video conferencing, which allows for the transfer of communication and identity cues holds threats to identity salience and stability. When starting to use rich communication media, transmitted identity cues can lead to the disconfirmation of previous assumptions on identity and result into category instability [13].

VT are often geographically dispersed in different countries, leading to a higher probability and degree of team diversity (e.g. in terms of culture) compared to traditional teams, which leads to an overall lower identity salience [13, 32, 33]. Further, diversity of team members can reduce their mutual socio-emotional understanding. Literature proposes that reduced socio-emotional understanding has a negative impact on team category salience, which in turn will decrease identification [4].

Further, VT are often set up in volatile organizational environments and with team members expecting the team constellation to change soon, thus reducing the motivation of the team members to identify [5]. Such changes in work context constantly challenge 
TI by continuously triggering identity reflection which influences the motivation as well as the verification stage of TI [3].

This long list of problems emerging along the TI process due to the specifics of virtual teams stresses the importance to find solutions to improve TI in virtual team contexts. Our research thus aims to provide an overview of known and available solutions to improve TI in virtual teams and point out potential areas for future research.

\section{$3 \quad$ Methodology}

In order to derive an overview of solutions to TI problems in virtual teams, we conducted an extensive literature review in combination with interviews with five case teams. As outlined in the introduction, this paper aims to address three issues with existing literature that guided our methodological approach. First, solutions to improve $\mathrm{TI}$ in VT are scattered presented in existing literature and an overview is missing on what problems in virtual TI are already addressed and what problems yet need solving. As a first step, we thus decided to conduct a literature review to get an overview of known solutions. Second, we decided to complement the literature review with empirical data, because a) we wanted to illustrate research results with concrete examples from practice, and b) there is recent criticism of research lacking behind solutions applied in practice [34], thus suggesting that the findings of our literature review need to be extended by recent developments in practice. Third, existing literature holds some paradoxes in suggested solutions (e.g. anonymity vs. sharing personal information) that require a critical review of their application and success in practice. This issue is addressed by our discussion of solutions presented in literature and their application in practice. Both, the literature review and interviews were conducted in 2019.

Data collection for literature review: Conducting our literature review, we followed the approach of Webster and Watson [35]. We applied the following search string: "(virtual OR hybrid OR remote) AND team* AND (identity OR identification)" to search for relevant papers in the databases Google Scholar, EBSCO and AISeL. The three databases were chosen due to their holistic compilation of recent research within the IS and other relevant disciplines. Additionally, we conducted forward and backward search from the central and high quality ranked seminal paper for TI by Fiol and O'Connor (2005) [13]. In total, 330 papers were screened by their title and abstract for their relevance on TI in VT. The screening process was stopped thereafter because the proportion of relevant papers decreased significantly and after reviewing, we expected no further insights. To ensure scientific rigor, only peer-reviewed articles were considered and we strived for a minimum C-ranking (VHB-Jourqual 3). Further, papers were excluded when their focus was not on identification and when there were no results when searching for the keyword "identi*" within the full text. Resulting from this, 95 papers were selected for further reading. Beyond this, papers, that did not deal with virtual or organizational contexts and papers, that did not focus on TI but solely on organizational- or self-identification, were not further included as these are different levels of identification [36]. This process resulted in 58 papers that were included in the literature review. The selected papers were published between 1984 and 2018 with

16th International Conference on Wirtschaftsinformatik,

March 2021, Essen, Germany 
ca. 73 percent dating back to 2010 or earlier. Further, 46 percent of the papers have a relation to IS discipline and almost 40 percent bear upon the Organization (ORG) and Human Resources (PERS) discipline. This shows that in fact, IS makes a significant contribution to research on the topic of TI in VT. Gilson, Maynard, Jones Young, Vartiainen and Hakonen [34] criticize that current literature is outdated. We therefore decided to complement our literature review with recent empirical data from case team interviews.

Data collection for complementary conducted interviews: We collected data from five virtual teams from different companies with the aim to extend identified solutions from our literature review and to illustrate the practical application of solutions with concrete examples. The five case teams were purposefully selected, following the criterion sampling logic [37], under following criteria: 1) the team had already started to collaborate virtually; 2) the physical contact with the remote team members is less than $50 \%$ of working time [based on 38] and 3) the team consists of at least four team members [based on $39,40,41$ ]. In addition, we aimed to increase the variety between case teams and deliberately considered structural differences (team- and organizational size, -structure and geographical dispersion) in our case team selection. The case teams were identified from the researchers private and professional network and conducting online research. For each case team, three team members including one member in a leading function were interviewed. The interviews followed a semi-structured interview guideline that followed the steps of the TI process. We asked open questions with the aim to identify problems to TI as well as applied solutions to improve TI in the respective TI process steps. As recommended for qualitative interviews [42], the guideline for team members was pilot-tested with one test interview partner, who is not part of the actual data collection sample. Further, the interview questions were continuously improved for the upcoming interviews during the constant review of conducted interviews. The interviews lasted on average one hour and were transcribed verbatim.

Data analysis: Our data analysis followed a combined inductive and deductive coding approach. That is, initially one researcher performed inductive coding of the gathered data, i.e. sections of the papers included in our literature review referring to problems and solutions for TI in VTs were coded thematically and code descriptions for determining the coding rules were created. Subsequently, the codes were refined and grouped into categories by two researchers. In line with Mayring [43], the codes as well as their description have been dynamically adapted and checked back during the coding process, grouping or breaking down codes into categories where appropriate. Conflicts in coding were resolved via discussing the respective coding rules and relating them back to existing concepts in literature. The interview data was coded as described for the literature review and finally the derived codes and categories were deductively matched to the codes from the literature overview. Our data analysis was guided by the TI process in that we related identified problems and solutions to the respective stages in which they were found to occur. 
Table 1. Overview of Investigated Case Teams.

\begin{tabular}{|c|c|c|}
\hline $\begin{array}{c}\text { Company } \\
\text { \# of employees }\end{array}$ & Industry and activities & $\begin{array}{l}\text { Distribution of } \\
\text { team members }\end{array}$ \\
\hline $\begin{array}{l}\text { Team A } \\
\sim 3,000 \\
\end{array}$ & $\begin{array}{l}\text { International } \mathrm{B} 2 \mathrm{C} \text { fashion retailer } \\
\text { with main focus on e-commerce }\end{array}$ & $\begin{array}{l}2 \text { collocated in Germany, } \\
4 \text { collocated in Bulgaria }\end{array}$ \\
\hline $\begin{array}{l}\text { Team B } \\
\sim 10\end{array}$ & $\begin{array}{l}\text { National online job platform for } \\
\text { apprenticeships and integrated } \\
\text { degree positions in Germany }\end{array}$ & $\begin{array}{l}2 \text { permanently remote, } \\
\text { others collocated in HQ }\end{array}$ \\
\hline $\begin{array}{l}\text { Team C } \\
\sim 10\end{array}$ & $\begin{array}{lcr}\text { B2B SaaS provider } & \text { for } \\
\text { automatically } & \text { market } \\
\text { company researches } & \text { and }\end{array}$ & $\begin{array}{l}1 \text { located in Mexico, } \\
\text { others collocated in } \\
\text { Germany }\end{array}$ \\
\hline $\begin{array}{l}\text { Team D } \\
\sim 115,000\end{array}$ & $\begin{array}{l}\text { Two merging companies in the } \\
\text { B2B and B2C energy producing, } \\
\text { supplying as well as infrastructure } \\
\text { and grid operating industry in } \\
\text { Germany }\end{array}$ & $\begin{array}{l}5 \text { members overall, all } \\
\text { work from different offices } \\
2 \text { work in the same city }\end{array}$ \\
\hline $\begin{array}{l}\text { Team E } \\
\sim 50\end{array}$ & $\begin{array}{l}\text { B2B content marketing service } \\
\text { and SEO solutions provider }\end{array}$ & $\begin{array}{l}\text { Fully virtual, all } 50 \\
\text { members work } \\
\text { permanently remote }\end{array}$ \\
\hline
\end{tabular}

\section{$4 \quad$ Results}

While we also identified general solutions to foster TI, e.g. longstanding collaboration and/or company affiliation, shared goal commitment, success and interpersonal sympathy, we in the following address solutions that were found to be specifically relevant within a virtual context or that specifically address problems stemming from virtuality. For increased readability, the identified solutions are presented along three categories: team actions, tools and digital leadership. These categories were derived by grouped solutions according to common characteristic and first and foremost follow the aim to structure our results for easier readability, thus don't raise claims on singularity or prominence.

Team actions describe organizational or structural solutions that teams can actively conduct to address problems in virtual TI. One action VT can perform to increase the interaction among all team members is to foster work interdependencies [41]. An increased amount of interactions between team members can solve many problems stemming from physical absence: frequent interaction can increase socio-emotional understanding amongst team members, gives opportunity to identify team characteristics and thereby fosters team identity salience. This solution therefore helps to improve TI by essentially supporting the social category formation and identity verification steps of the TI process. When enforced for all team members, increased amount of interactions can resolve unequal contact and thus the potential for subgroup identification in hybrid teams [32]. Team D for example is working in different tandem constellations with each team member at a different point in time. Further, actively 
initiating frequent communication can help to reduce a feeling of separateness that is caused by physical absence. Frequent communication increases personal interaction and thus counteracts the problem of missing possibilities for spontaneous and unplanned meetings in virtual collaboration [38]. Therefore, team B established regular update calls as well as the possibility to contact each other for spontaneous communication throughout the working day. Some of their calls even last for hours, which again improves TI by supporting the social category formation and verification steps. In addition, conversations on non-work-related topics were also mentioned as essential for building TI in VT [38]. Non-work-related communication helps to get to know the team members better on a more personal level. Proactive communication and active questioning of latest happenings before or at the end of a call, as performed in team D, give the team members the necessary scope to implement this action. Further, sharing non-work-related pictures in group chats and using informal language further promote communication on non-work-related topics, as performed by team A.

Next, interactions can be further increased via physical meetings and (virtual) team events. Physical meetings, especially at the beginning of the collaboration, can foster a mutual understanding for individual behaviors and communication characteristics and thus reduce future misunderstandings [5]. However, they require travel time, which might lower the intrinsic motivation to participate. In order to decrease this burden, offering team events on a voluntary basis to decrease the feeling of obligation but convey the idea of an invitation is proposed by team B. Team C even proposes to conduct content-driven team events virtually.

Further actions reduce the risk of miscommunication by addressing the lack of relevant communication cues. Technological media limit the transfer of communication cues that are relevant to grasp the meaning of words. Giving each other regular acknowledgement and feedback [5] in a kind way generates more clarity and, as the interview results show, helps to establish a common understanding on terminologies. Beyond, establishing an open team culture provides the team members with psychological safety that makes them more comfortable to address their concerns openly [44]. Team E for example established an error tolerance as part of their feedback- and open team culture by inviting the team members to openly share their challenges within the team to give and receive support. Beyond, team D points out the importance to get mutual cultural understanding if the team is international.

Additional actions to improve TI in VT stated in literature include first, the transfer of employees between different collocated sub-groups in order to build up communication networks [32]. If within a team, sub-groups have established that hinder the overall TI, literature suggests to even restructure the team by relocating employees of sub-groups to the location of other team members [23]. Next, being permanently available for collaboration and communication is found to be helpful for TI as well [45]. However, this can increase the team members' perceived stress level and thus have negative consequences on their TI [46]. In order to foster mutual understanding by proactively sharing contextual information, i.e. information, that is not available to all team members due to geographic distance, such as environmental events, it is proposed to train the team members on their awareness on the importance of this issue [32]. Beyond this, enabling the members to communicate and vote in certain aspects 
anonymously leads to a more open communication [2]. Another aspect that is promoted in literature is the fact that teams should differentiate themselves from outgroups and outline their benefits compared to other teams. This is especially relevant for the phases of category formation and comparison [5].

Tools are technical solutions that can be implemented to support TI in VT. First, information archives, issue tracking technologies and chat programs can positively contribute to TI, as the interview results show. Internationally distributed teams may face the challenge of being located across different time zones and thus having differences in working hours. This makes it challenging for them to organize meetings and conversations as well as to perform knowledge management as the interviewees in team $\mathrm{C}$ stated. Team A, for example, uses group chats that allow for a team-wide transparent communication and switched its chat program to a tool that enables the functionality of accessing the chat history. Issue tracking technology generates awareness on the fact that all team members together contribute to achieve the team goal and thus helps to create membership awareness as team B states in the interviews. This makes the team aspect even more visible to the members and thus increases team salience. Team B tracks the progress of the individual tasks in a central program where they also store all relevant related information to these tasks. Further, in team E chat channels are dedicated to specific non-work-related topics to facilitate communications on those. Further, the interview results show that the integration of technological features into communication media that show the respective times of availability of each team member is a helpful tool, especially for internationally distributed teams. Team E integrated a time zone tracking feature into their communication tool which increased the awareness, enhances mutual understanding for possibly delayed replies, and facilitates the coordination of finding an appointment date.

Apart from this, some advanced technological communication tools allow for the transfer of more communication cues. While in audio conferences, gestures and mimes can only be transferred by acoustic signals, video conferences provide additional visual components, which make gestures and facial expressions directly visible [47]. In both however, there is a strong dependence on connectivity and equipment quality which is nowadays still an issue. Team D sometimes made use of telepresence technology. However, this technology is rarely applied due to limited facility availability. Moreover, virtual reality (VR) features [48], such as avatars [49], can support communication beyond words.

In addition, the interviewees state that real-time document sharing functions can help to reduce misunderstandings by allowing for simultaneous access to documents. In the interviews it was stated that without physical meetings in which team members can look at the same device, discussing and editing documents is prone to miscommunication without real-time sharing functionalities. Team B highlights the importance of this feature in remote work. Additionally, literature proposes the integration of automatic team update notifications that inform all team members on the latest happenings within the team [45]. However, none of the teams interviewed is currently using such a feature.

Enterprise social networks, i.e. web-based platforms that allow workers to communicate via messages, identify relevant coworkers, and share information via 
posts and files [50], offer an integration of all technological functions that were mentioned in this paragraph. Therefore, they play a key role in TI building in VT. Enterprise social network profiles that offer a platform for sharing personal information as well as a newsfeed for the remote locations to stay informed about critical happenings can be supportive to foster non-work-related communication. According to the interview outcomes, detecting common fields of personal interests can help to overcome the issue of missing gambits when not being located at the same place. Team $\mathrm{C}$ has integrated personal profiles in their intranet, allowing each team member to share all kinds of personal information in different formats (video, pictures, text etc.).

Digital leadership describes all actions that can be especially performed by the team leader. As the interview results show, leaders can act as a role model by expressing their identification with the team towards the members and thereby positively influence the team members to act the same way. Team B's team leader initiated the sharing of non-work-related information to inspire the team members to do the same. As proposed in literature, an aptitude-based team member selection when setting-up the team is a fundament to ensure that the team members are capable to work in virtual settings. Optimally, the team leader should be experienced in leading in virtual settings [51].

Next, individual inclusion of all team members into communication is an essential activity [52]. By communicating thoughtfully with regard to honesty and friendliness in wording [53] and parallelly minimizing non-transferrable communication cues, as shown in the interviews, the leader can make sure to involve all team members equally. Especially in giving feedback, thoughtful and honest communication is very important according to team $\mathrm{E}$. With regards to onboarding, ensuring an introduction of new team members to the team is of high relevance as the interviews show. In this way, the basis for future interaction is laid. Team A shows that actively introducing new members to the team positively contributes to TI. Further, the interview results show that demanding and fostering active participation from all team members increases the interaction within the team and thereby improves TI. When the team leader in team A demanded active participation, the perceived TI within the team was stronger compared to times, when participation was not actively forced.

Finally, as stated in the interviews, measuring $T I$ ensures to stay informed about the current TI situation. Having information on the current TI within the team helps to take additional solutions in time, if necessary. In team E, for example, TI is tracked regularly by small weekly surveys which ask the team members to reflect on the previous week, plan the next week and share their feelings. Additionally, more encompassing quarterly surveys are conducted, to explicitly ask for feedback and improvement potential as well as the team member's wellbeing.

In the theoretical background section, we outlined problems in TI due to the virtual context of teams in detail along the TI process. In the subsequent table 2, we now link all identified solutions to improve TI in VT to the respective problems these solutions solve. The thereby derived matrix provides a comprehensive overview of problems and solutions in virtual TI and gives insight into the distribution of findings from literature and our conducted interviews. 
Table 2. Matrix linking solutions to problems in virtual team identification.

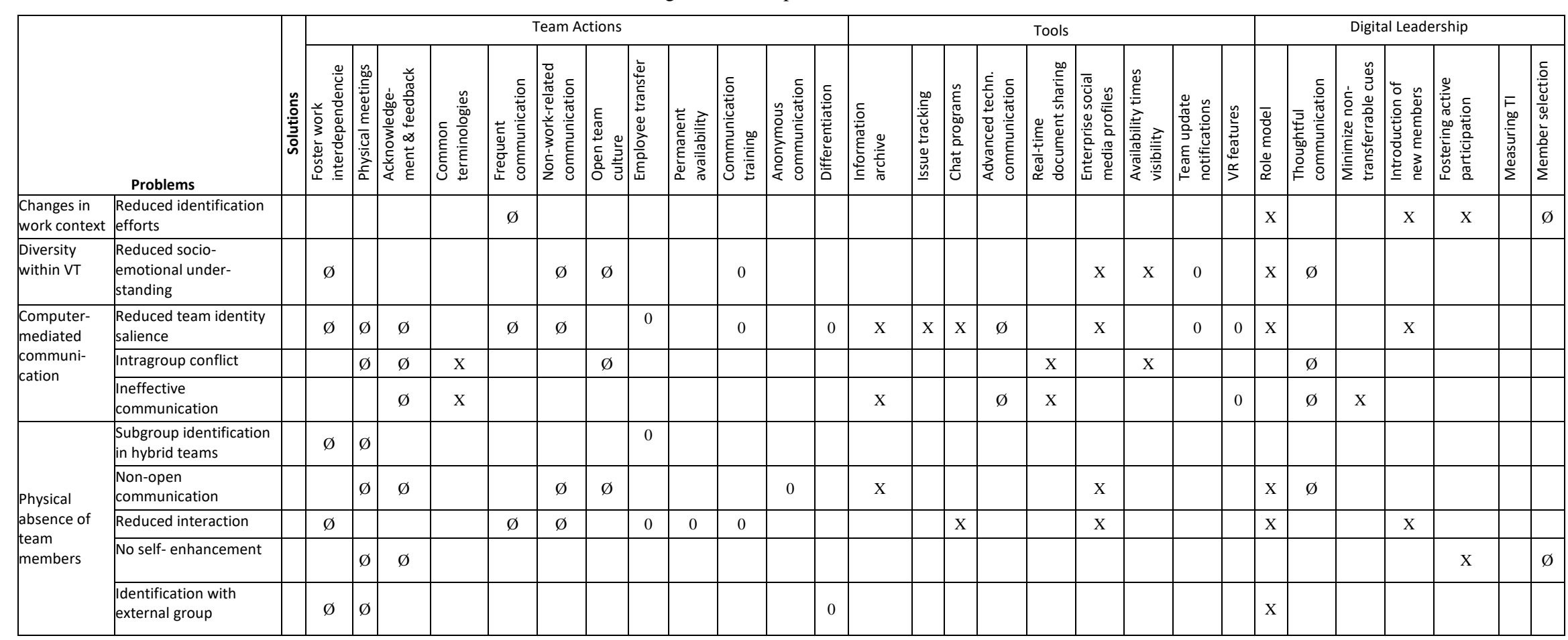

Legend: „0“ Solutions only in literature review; „X“ Solutions only from interviews; „Ø“ Solutions from literature review and interviews

16th International Conference on Wirtschaftsinformatik,

March 2021, Essen, Germany 


\section{Discussion}

Comparison of solutions from literature and their application in our empirical interview research: Comparing the identified solutions to improve TI in VT from literature and the insights gained from the conducted interviews with our case teams (see Table 2 for an overview), some consensus as well as new insights can be derived. First, we found congruence in literature and practice on the effectiveness of several solutions to improve TI in VT, namely: foster work interdependencies, encourage acknowledgement and feedback, introduce audio \& video-conferencing, implement communities for mutual learning, e.g. working-tandems for knowledge-exchange, as well as real-time document sharing.

We further found some solutions that were proposed in literature but not applied in practice. While literature suggests to differentiate the team from others to decrease the risk of outgroup identification [53], we found no such application in practice but rather solutions to increase ingroup awareness, such as team-building events. One potential reason for this could be that ingroup activities might be seen as socially more accepted than differentiation. Another reason might be that our interview partners did not perceive the presence of outgroups as threat for TI. Another proposition by literature for hybrid VT is to transfer employees between sites to trigger exchange between locational sub-groups. In order to foster the sharing of contextual information, literature proposes to train the team members. In practice, sharing of contextual information is performed in dedicated time frames in regular meetings.

Further, our interview data reveals several solutions to improve TI that have yet not been mentioned in literature. The interview results point out the relevance for real-time document sharing and the possibilities to enable simultaneous accesses to one document for several team members. Especially the topic of digital leadership as support for TI in VT thus seems a promising field for future research. Interestingly, a lot of our studied case teams still relied on eventually bringing team members physically together, e.g. via onboarding events. We therefore call for future research to further investigate this issue in order to derive a better understanding of which elements of TI can and which cannot be virtually substituted. Further, for some of the problems to TI in VT, we identified only a small number of potential solutions and therefore call for future research on how these problems might be solved. Especially for the problem of reduced identity efforts in VT, all our identified solutions stem from our interviews revealing a lack of knowledge in the existing body of literature. In terms of onboarding new employees in VT, it would be helpful to find out more about solutions that help the new employees to identify with the team in a situation where the values for collaboration are usually already set.

Applied solutions might trigger new problems: The insights from the conducted interviews with our case teams reveal an issue that is yet unaddressed in literature: that the applied solutions potentially lead to further problems. Three problems triggered by solutions to improve TI seem to be especially challenging because there are no immediate solutions available. As outlined, the implementation of IT can solve many 
issues in virtual TI, however this can trigger new problems in form of connection quality, technological incompatibility, and (technological) facility availability. The effectivity of audio-, video- and telepresence conferences is highly dependent on good internet connectivity quality. While this factor is internally influenceable by investments in IT quality, the issue is however also dependent on external factors, such as the maximum available internet speed, which seems to be still a big issue nowadays. Moreover, technological incompatibility is an issue that cross-company teams might face when there is no common base of technological tools and if the different internal rules of the companies hamper tool integration. Third, offering facilities, both technological, such as equipment for telepresence, as well as spatial, like quiet office spaces, comes along with high investment costs. In addition, the individual working conditions for employees who work from home can be very different and make it especially hard to provide them with access to such facilities. In summary, applied solutions to TI in VT might evoke new problems and although existing solutions can help to overcome some of the issues, not all problems can be fixed the short-term nor are they all fully influenceable internally. We therefore call for future research to explicitly consider these (often technology-related) issues when identifying or proposing solutions for virtual TI. Future research should set a strong focus on providing insight into what requirements technological tools have to meet in order to be used in VT.

Discussion opportunities for TI due to virtuality: Contrary to what was expected when researching problems and solutions for TI issues in VT, the interview results provide plentiful insights on opportunities for TI that occur due to the virtual context. First, being physically distant from superiors creates a feeling of freedom in action, fosters creativity and the implementation of own ideas. This increases the degree of personal contribution to the team success. Second, communicating over distance decreases the inhibition level of posing questions and representing a specific point of view in discussions. Even though this fact is not explicitly stated as an opportunity in literature, there are proposals on anonymity features that could make this opportunity possible [2]. However, communication over distance can also have downsides to TI, as it is more difficult to casually address more critical issues in an informal atmosphere. Finally, using video conferences in the home office allows much more private insights into the private circumstances of the team members than conversations onsite would allow for. Thus, team members have the chance to get to know each other on an even more private level.

\section{Contribution}

In conclusion, our study combines an extensive literature review with interviews conducted with five case teams to identify solutions to improve TI in VT and give insights into their practical application. Based on the TI process, we first identified problems to TI stemming from a virtual context and then linked these problems to potential solutions identified in our research. Overall, our research provides an 
overview of known solutions to problems in virtual TI that allows us to identify promising areas for future research.

With increasing digitalization and ever more teams working together, our work contributes to research on digital work. First, our study extends the understanding of the TI process by explicitly considering also the phase of identification enactment and verification which is critical for long-term TI preservation. Second, we compile a list of problems to TI in VT and link them to their occurrence in the TI process. Third, we provide a comprehensive overview of known solutions to problems in virtual $\mathrm{TI}$ and exemplify their application in practice. Our results go beyond a mere literature review and also integrate insights from interview data collected at five case teams, our study reveals new solutions and opportunities that enrich the scope of available solution solutions as they have not been found in literature before. These insights can give hands-on guidance for practitioners in how existing issues with TI in VT can be solved. Based on our results, we further outline promising areas for future research due to nonattended problems and emerging issues that teams might be confronted with when deciding to apply these solutions.

We further acknowledge some limitations to our study. First, due to the enormous amount of search results we limited our screening efforts to 330 papers as basis for our literature review as no further insights thereafter were expected. Future research could however extend our literature review by including more papers, e.g. also from the discipline of psychology. Second, we extended our literature review with insights from five case teams. Due to the limitations given by the empirical interview research design, the insights on the application of solutions to improve TI in VT are therefore not generalizable. Future research could extend our findings with insights from more cases via e.g. a quantitative assessment. However, we believe that our qualitative approach allowed us to gain insights into the practical application of solutions stated in literature and identify new solutions of how to improve TI in VT.

\section{References}

1. Lurey, J.S., Raisinghani, M.S.: An Empirical Study of Best Practices in Virtual Teams. Information \& Management 38, 523-544 (2001)

2. O'Leary, M.B., Cummings, J.N.: The Spatial, Temporal, and Configurational Characteristics of Geographic Dispersion in Teams. MIS Quarterly 433-452 (2007)

3. Thatcher, S.M., Zhu, X.: Changing Identities in a Changing Workplace: Identification, Identity Enactment, Self-Verification, and Telecommuting. Academy of Management Review 31, 1076-1088 (2006)

4. Shapiro, D.L., Furst, S.A., Spreitzer, G.M., Von Glinow, M.A.: Transnational Teams in the Electronic Age: Are Team Identity and High Performance at Risk? Journal of Organizational Behavior 23, 455-467 (2002)

5. Sivunen, A.: Strengthening Identification with the Team in Virtual Teams: The Leaders' Perspective. Group Decision and Negotiation 15, 345-366 (2006)

6. Han, G., Harms, P.D.: Team Identification, Trust and Conflict: A Mediation Model. International Journal of Conflict Management 21, 20-43 (2010) 
7. Kramer, R.M.: Intergroup Relations and Organizational Dilemmas: The Role of Categorization Processes. In: L. L. Cummings, Staw, B.M. (eds.) Research in Organizational Behavior, vol. 13, pp. 191-228. JAI, Greenwich, CT (1991)

8. Lembke, S., Wilson, M.G.: Putting the "Team" into Teamwork: Alternative Theoretical Contributions for Contemporary Management Practice. Human Relations 51, 927-944 (1998)

9. Moore, D.A., Kurtzberg, T.R., Thompson, L.L., Morris, M.W.: Long and Short Routes to Success in Electronically Mediated Negotiations: Group Affiliations and Good Vibrations. Organizational Behavior and Human Decision Processes 77, $22-43$ (1999)

10. Eckel, C.C., Grossman, P.J.: Managing Diversity by Creating Team Identity. Journal of Economic Behavior \& Organization 58, 371-392 (2005)

11. Turner, J.C.: Towards a Cognitive Redefinition of the Social Group. In: Tajfel, H. (ed.) Social Identity and Intergroup Relations, pp. 15-40. Cambridge University Press, Cambridge (1982)

12. Dutton, J.E., Dukerich, J.M., Harquail, C.V.: Organizational Images and Member Identification. Administrative Science Quarterly 39, 239-263 (1994)

13. 13. Fiol, C.M., O'Connor, E.J.: Identification in Face-to-Face, Hybrid, and Pure Virtual Teams: Untangling the Contradictions. Organization Science 16, 19-32 (2005)

14. Hogg, M.A.: Subjective Uncertainty Reduction Through Self-Categorization: A Motivational Theory of Social Identity Processes. European Review of Social Psychology 11, 223-255 (2000)

15. Tajfel, H.: Social Identity and Intergroup Behaviour. Social Science Information 13, 65-93 (1974)

16. Turner, J.C., Oakes, P.J., Haslam, S.A., McGarty, C.: Self and Collective: Cognition and Social Context. Personality and Social Psychology Bulletin 20, 454-463 (1994)

17. Tajfel, H., Turner, J.C.: An Integrative Theory of Intergroup Conflict. In: Austin, W.G., Worchel, S. (eds.) The Social Psychology of Intergroup Relations, pp. 56-65. Brooks Cole, Monterey (1979)

18. Tajfel, H.: Social Psychology of Intergroup Relations. Annual Review of Psychology 33, 139 (1982)

19. Allen, N.J., Meyer, J.P.: The Measurement and Antecedents of Affective, Continuance and Normative Commitment to the Organization. Journal of Occupational Psychology 63, 1-18 (1990)

20. Tajfel, H.: Social Categorization, Social Identity and Social Comparison. In: Tajfel, H. (ed.) Differentiation Between Social Groups: Studies in the Social Psychology of Intergroup Relations, pp. 61-76. Avademic Press, London (1978)

21. Lembke, S., Wilson, M.: The Psychology of Teamthink: A Journey Towards Highly Productive Teamwork. The 1996 International Conference on Work Teams. Proceedings. The University of North Texas, (1996)

22. Reicher, S.D., Spears, R., Postmes, T.: A Social Identity Model of Deindividuation Phenomena. European Review of Social Psychology 6, 161-198 (1995)

23. Webster, J., Wong, W.: Comparing Traditional and Virtual Group Forms: Identity, Communication and Trust in Naturally Occurring Project Teams. The International Journal of Human Resource Management 19, 41-62 (2008)

24. Kirkman, B.L., Gibson, C.B., Kim, K.: Across Borders and Technologies: Advancements in Virtual Teams Research. The Oxford Handbook of Organizational Psychology, vol. 2, (2012) 
25. Kahai, S.S., Cooper, R.B.: Exploring the Core Concepts of Media Richness Theory: The Impact of Cue Multiplicity and Feedback Immediacy on Decision Quality. Journal of Management Information Systems 20, 263-299 (2003)

26. Rafaeli, S., Ravid, G.: Information Sharing as Enabler for the Virtual Team: An Experimental Approach to Assessing the Role of Electronic Mail in Disintermediation. Information Systems Journal 13, 191-206 (2003)

27. May, A., Carter, C.: A Case Study of Virtual Team Working in the European Automotive Industry. International Journal of Industrial Ergonomics 27, 171-186 (2001)

28. Raghuram, S., Hill, N.S., Gibbs, J.L., Maruping, L.M.: Virtual Work: Bridging Research Clusters. Academy of Management Annals 13, 308-341 (2019)

29. Andres, H.P.: The Impact of Communication Medium on Virtual Team Group Process. Information Resources Management Journal (IRMJ) 19, 1-17 (2006)

30. Panteli, N., Davison, R.M.: The Role of Subgroups in the Communication Patterns of Global Virtual Teams. IEEE Transactions on Professional Communication 48, 191-200 (2005)

31. Bhappu, A.D., Crews, J.M.: The effects of communication media \& conflict on team identification in diverse teams. In: Proceedings of the 38th Annual Hawaii International Conference on System Sciences. IEEE, NW Washington, DC United States (2005)

32. Cramton, C.D., Hinds, P.J.: Subgroup Dynamics in Internationally Distributed Teams: Ethnocentrism or Cross-National Learning? Research in Organizational Behavior 26, 231263 (2005)

33. Workman, M.: The Effects from Technology-Mediated Interaction and Openness in Virtual Team Performance Measures. Behaviour \& Information Technology 26, 355-365 (2007)

34. Gilson, L.L., Maynard, M.T., Jones Young, N.C., Vartiainen, M., Hakonen, M.: Virtual teams research: 10 years, 10 themes, and 10 opportunities. Journal of Management 41, 13131337 (2015)

35. Webster, J., Watson, R.T.: Analyzing the Past to Prepare for the Future: Writing a Literature Review. MIS Quarterly xiii-xxiii (2002)

36. Miscenko, D., Day, D.V.: Identity and Identification at Work. Organizational Psychology Review 6, 215-247 (2016)

37. Patton, M.Q.: Qualitative Research and Evaluation Methods Sage Publications, Thousand Oaks (2002)

38. Dubé, L., Robey, D.: Surviving the Paradoxes of Virtual Teamwork. Information Systems Journal 19, 3-30 (2008)

39. Cramton, C.D.: The Mutual Knowledge Problem and its Consequences for Dispersed Collaboration. Organization Science 12, 346-371 (2001)

40. Millward, L.J., Haslam, S.A., Postmes, T.: Putting Employees in Their Place: The Impact of Hot Desking on Organizational and Team Identification. Organization Science 18, 547-559 (2007)

41. O'Leary, M.B., Mortensen, M.: Go (Con) Figure: Subgroups, Imbalance, and Isolates in Geographically Dispersed Teams. Organization Science 21, 115-131 (2010)

42. Hennink, M., Hutter, I., Bailey, A.: Qualitative research methods. SAGE Publications Limited (2020)

43. Mayring, P.: Qualitative Inhaltsanalyse. Grundlagen und Techniken. 12., überarbeitete Auflage. Beltz. Weinheim (2015)

44. Brandon, D.P., Pratt, M.G.: Managing the Formation of Virtual Team Categories and Prototypes by Managing Information: A SIT/SCT Perspective. Academy of Management Proceedings, vol. 1999, pp. D1-D6 (1999) 
45. Wu, Y., Cui, T., Deng, Y.: How Does Mobile Computing Develop Transactive Memory in Virtual Team? A Social Identification View. Thirty Seventh International Conference on Information Systems, Dublin (2016)

46. Fonner, K.L., Roloff, M.E.: Testing the Connectivity Paradox: Linking Teleworkers' Communication Media Use to Social Presence, Stress from Interruptions, and Organizational Identification. Communication Monographs 79, 205-231 (2012)

47. Pauleen, D.J., Yoong, P.: Facilitating virtual team relationships via Internet and conventional communication channels. Internet Research: Electronic Networking Applications and Policy 11, 190-202 (2001)

48. Guegan, J., Segonds, F., Barré, J., Maranzana, N., Mantelet, F., Buisine, S.: Social identity cues to improve creativity and identification in face-to-face and virtual groups. Computers in Human Behavior 77, 140-147 (2017)

49. Ellis, J.B., Luther, K., Bessiere, K., Kellogg, W.A.: Games for virtual team building. In: Proceedings of the 7th ACM Conference on Designing Interactive Systems, pp. 295-304. Cape Town South Africa (2008)

50. Leonardi, P.M., Huysman, M., Steinfield, C.: Enterprise social media: Definition, history, and prospects for the study of social technologies in organizations. Journal of ComputerMediated Communication 19, 1-19 (2013)

51. Rezgui, Y.: Exploring virtual team-working effectiveness in the construction sector. Interacting with Computers 19, 96-112 (2007)

52. Scott, M.E.: "Communicate through the roof": A case study analysis of the communicative rules and resources of an effective global virtual team. Communication Quarterly 61, 301318 (2013)

53. Hallier, J., Baralou, E.: Other voices, other rooms: differentiating social identity development in organisational and Pro-Am virtual teams. New Technology, Work and Employment 25, 154-166 (2010) 